\title{
The Assessment and Selection of Potential Rehabilitation Patients in Acute Hospitals: A Literature Review and Commentary
}

\author{
Peter W. New ${ }^{*}$ \\ Acute Rehabilitation, Continuing Care Program, Kingston Centre, Southern Health, Melbourne, Australia \\ Spinal Rehabilitation Unit, Caulfield Hospital, Alfred Health, Victoria, Australia \\ Departments of Medicine and Epidemiology \& Preventive Medicine, Monash University, Victoria, Australia
}

\begin{abstract}
Objective: Literature review on the assessment and selection of adults in acute hospitals regarding the need for inpatient rehabilitation.

Data Sources: Electronic literature search preformed using Medline (1966-2008), Embase (1980-2008) and CINAHL (1982-2008) databases. Search terms were: 'patient selection', 'patient assessment', and 'rehabilitation'. Reference section of relevant articles screened for additional useful publications. A selection of textbooks on rehabilitation medicine was also reviewed for pertinent information or related articles.

Inclusion Criteria: Search limited to articles or abstracts published in English involving the assessment of adults in acute hospitals concerning selection for inpatient rehabilitation. No restriction on type of study methodology.

Data Extraction: No data extraction performed. No randomized controlled trials identified. Three non-randomized clinical trials were located. Eight prospective and one retrospective cohort study were found. Thirteen relevant non-experimental papers were also identified.

Data Synthesis: No formal data synthesis because the methodological quality of identified papers was not high enough to perform formal systematic review. Therefore, a thematic synthesis was performed of relevant identified information and suggestions provided based on the literature and the clinical experience of the author.

Conclusions: The assessment of patients in acute hospital for rehabilitation is an important skill. It has the potential to improve patient outcomes. There is a need for further research in this area.
\end{abstract}

Keywords: Rehabilitation, patient selection, patient assessment, process assessment, review.

\section{INTRODUCTION}

For a topic of such great importance, there is surprisingly little in the rehabilitation medicine literature on the assessment of patients in acute hospital regarding their need for rehabilitation. In this context, rehabilitation assessment is the process of formulating an opinion about the need for rehabilitation, and if indicated, where is the ideal setting for this to occur. In many situations this assessment is relatively straightforward. In some circumstances, however, it can be challenging and time-consuming.

The assessment and selection of patients for rehabilitation is a very important skill that takes years to learn and refine. This 'gate keeper' role ensures that only patients with severe activity limitations and a need for a multidisciplinary/interdisciplinary team approach are admitted, and that patients who are more appropriate for other settings are triaged accordingly. Health care is an expensive and limited resource. With the aging of the worlds' population [1] and the anticipated increase in demand for rehabilitation, the

*Address correspondence to this author at the Acute Rehabilitation, Continuing Care Program, Kingston Centre, Warrigal Rd, Cheltenham, Victoria 3192, Australia; Tel: 61-3-9265 1000; Fax: 61-3-9265 1430;

E-mail: peter.new@southernhealth.org.au responsibility to use health care resources in the most appropriate way will become even more important.

Because of the above, it was felt appropriate to perform a literature review on the assessment of patients in acute hospitals regarding the need for rehabilitation. The primary objective of this paper was to review the literature on the assessment of adults in acute hospitals regarding the need for 'fast steam' or acute rehabilitation. Secondary objectives were to give suggestions regarding aspects of this topic where evidence is lacking based on literature reports and the clinical experience of the author. Another objective was to suggest a framework for further research on this topic. Areas covered in the review include ethical considerations, who should perform rehabilitation assessments, what issues they need to consider, practical aspects of the assessment, and the aims and benefits of the consultative component of the assessment.

\section{METHODS}

\section{Literature Search}

An electronic literature search was preformed of the Medline (1966-2008), Embase (1980-2008) and CINAHL 
(1982-2008) databases. Search terms used were 'patient selection', 'patient assessment', and 'rehabilitation'.

The search was limited to articles or abstracts published in English involving the assessment of adults in acute hospitals regarding the selection and assessment for inpatient rehabilitation. It was determined that all study methods and reports relevant to this topic identified by the literature search would be included. This decision was made because it was anticipated that there would be a lack of high quality studies on this topic. The reference section of all relevant articles was examined for additional useful publications. Furthermore, available books on rehabilitation medicine were screened for pertinent information or related articles. Articles not published in English, and those involving drug and alcohol rehabilitation were excluded. Although the focus of this review was on the selection of potential candidates for 'fast steam' (acute) rehabilitation, it was determined that manuscripts could be included from the geriatric field if they provided information that was relevant to this review that were not identified in other included manuscripts.

\section{RESULTS}

\section{Overview of the Literature Search}

No randomized controlled trials involving the selection of rehabilitation patients in acute hospital were identified. Three non-randomized clinical trials were located [2-4]. Eight prospective [5-12] and one retrospective [13] cohort study was found. Thirteen relevant non-experimental papers were also located [14-26]. A summary of the relevant papers located by the literature search is shown in Table 1.

Many rehabilitation medicine textbooks [27-29] and handbooks [30-33] did not cover the topic, and one focused primarily on the ethical and financial aspects [34]. Only two textbooks were found that covered this topic in detail [35, 36].

The methodological quality of identified papers did not permit a meta-analysis or formal systematic review. Therefore, it was decided to synthesize the relevant papers identified thematically and provide suggestions based on the literature and the clinical experience of the author.

\section{DISCUSSION}

One useful definition of inpatient rehabilitation potential is "the prognostic indicator of how well a patient will perform within a standard inpatient rehabilitation program... an estimation of the patient's personal strengths (i.e. level of motivation/cooperation, cognitive status, and personality constellation), medical complications, and family support as they interface with the therapies and rehabilitation environment. In essence, the assessment of rehabilitation potential estimates the individual's capacity of cooperating with a rehabilitation program and making measured functional gains..."[18].

A key consideration when appraising studies in this area is that there is no accepted standard definition regarding what is meant by 'appropriate for rehabilitation'. Criteria can vary between different institutions or health care settings for various reasons. These include financial, resource availability, or specialty program focus. Underlying factors in the decision-making process may include a combination of con- siderations of effectiveness, benefit, cost-effectiveness and cost-benefit. Similarly, there is no internationally accepted definition of what constitutes a standard rehabilitation program.

\section{Ethical Considerations}

Many authors have highlighted the ethical imperatives arising during the process of rehabilitation patient selection $[15-17,19,20,37]$. Issues addressed have included the importance of considering resource limitations; needing to cover medical and non-medical factors; the potential for injustice and bias; the tension between utility and beneficence; and the rights, duties and responsibilities of those involved in patient selection. It is a given that there is absolutely no place at all in the selection process for any consideration of factors such as gender, religion, ethnicity, personality, level of wealth, power, or intelligence.

\section{Who should Assess for Rehabilitation?}

It has been reported that patients deemed appropriate for rehabilitation at the time of discharge by a multidisciplinary team have more function gains, although they were more disabled and had a shorter length of stay (LOS), compared to those patients deemed not appropriate for rehabilitation [8]. There are several methods that have been used to assess patients for rehabilitation. These are assessment by a doctor, a specialized nurse, or a multi-disciplinary team. In addition, some centers use an electronic triage system to assist in optimizing the timing and selection of patients. These will be elaborated on below.

In a study conducted 30 years ago, no improvement was reported in the LOS or functional outcomes achieved after the implementation of medical, neurological and social screening of stroke patients to select those most likely to benefit from rehabilitation [2]. There were numerous methodological issues with this study, however, this is the only evaluation of this type located.

In a non-randomized trial comparing outcomes for stroke patients admitted after assessment by either a nurse or rehabilitation physician, there where no significant differences in the judged appropriateness for admission, LOS, or discharge home rates according to who performed the assessment [3]. A recent study reported poor agreement between rehabilitation team members regarding which patients were considered appropriate for admission [9]. This study, however, involved only 27 patients admitted to a geriatric rehabilitation ward and the findings may not be generalizable to other rehabilitation settings, particularly, those focusing on specific impairments or a younger patient cohort.

In many countries admission to inpatient rehabilitation is arranged via referral to a rehabilitation consultant physician (physiatrist), a supervised trainee, or sometimes a geriatrician. A rehabilitation consultant or trainee has specialized rehabilitation medicine knowledge and expertise. This can be extremely important in providing consultative advice on patient management in the acute hospital setting. This expertise comes at higher cost than assessments conducted by alternative professional groups, such as nursing. If there is inadequate medical staffing there can be delays between referral and assessment that may increase acute hospital LOS. 
Table 1. Summary of Key Features of Relevant Publications on the Selection of Acute Hospital Patients for Inpatient Rehabilitation

\begin{tabular}{|c|c|c|c|c|c|}
\hline Author & Year & Country & Study Type & Patients/Setting & Summary \\
\hline Feingeson [2] & 1977 & USA & $\begin{array}{l}\text { Non-randomized } \\
\text { clinical trail }\end{array}$ & $\begin{array}{c}\text { Stroke } \\
\text { Rehabilitation }\end{array}$ & $\begin{array}{c}\text { Comparison of outcomes between patients unscreened }(\mathrm{n}=248) \\
\text { for admission and those with medical, neurological and social } \\
\text { screening }(\mathrm{n}=318) \text {. No improvement in LOS or outcomes with } \\
\text { screening. }\end{array}$ \\
\hline Poduri [3] & 1996 & USA & $\begin{array}{l}\text { Non-randomized } \\
\text { clinical trail }\end{array}$ & $\begin{array}{c}\text { Stroke } \\
\text { Rehabilitation }\end{array}$ & $\begin{array}{l}\text { Comparison of outcomes in patients with } 2 \text { different approaches } \\
\text { of admission to a rehabilitation unit. Admission screening by } \\
\text { rehabilitation consultant }(\mathrm{n}=93) \text { or nurse practitioner }(\mathrm{n}=93) \text {. } \\
\text { No difference in LOS, patients considered appropriate for ad- } \\
\text { mission, or discharged home. Patients screened by rehabilitation } \\
\text { consultant met more goals. }\end{array}$ \\
\hline Kossovsky [4] & 2002 & Switzerland & $\begin{array}{l}\text { Non-randomized } \\
\text { clinical trail }\end{array}$ & $\begin{array}{l}\text { Rehabilitation } \\
\text { patients }\end{array}$ & $\begin{array}{l}\text { Modifications were made to processes of care regarding transfer } \\
\text { to rehabilitation hospital. The impact of these modifications was } \\
\text { then assessed }(\mathrm{n}=498) \text { using an Appropriateness Evaluation } \\
\text { Protocol. Inappropriate hospital days reduced from } 28 \text { to } 25 \% \\
(\mathrm{P}=0.12) .\end{array}$ \\
\hline Tamler [5] & 1992 & USA & $\begin{array}{l}\text { Prospective } \\
\text { cohort }\end{array}$ & $\begin{array}{l}\text { Mixed impairments } \\
\text { Rehabilitation }\end{array}$ & $\begin{array}{l}\text { Prediction of discharge to home } v s \text { nursing home after inpatient } \\
\text { rehabilitation using questionnaire administered after admission } \\
(\mathrm{n}=79) \text { examining families willingness to provide care and } \\
\text { assistance after discharge. }\end{array}$ \\
\hline Kala [6] & 1993 & UK & $\begin{array}{l}\text { Prospective } \\
\text { cohort }\end{array}$ & $\begin{array}{l}\text { Stroke (geriatric: } \\
\quad>75 \text { years). } \\
\text { Rehabilitation }\end{array}$ & $\begin{array}{c}\text { Prognostic and Barthels index scores after admission to rehabili- } \\
\text { tation }(\mathrm{n}=96) \text { accessed for predicting outcome and activities of } \\
\text { daily living at discharge and } 16 \text { weeks. }\end{array}$ \\
\hline Mauthe [7] & 1996 & USA & $\begin{array}{l}\text { Prospective } \\
\text { cohort }\end{array}$ & $\begin{array}{c}\text { Stroke. } \\
\text { Rehabilitation }\end{array}$ & $\begin{array}{l}\text { FIM scores on admission }(\mathrm{n}=298) \text { analyzed to determine items } \\
\text { most useful in predicting discharge destination. }\end{array}$ \\
\hline Poduri [8] & 1996 & USA & $\begin{array}{l}\text { Prospective } \\
\text { cohort }\end{array}$ & $\begin{array}{l}\text { Mixed impair- } \\
\text { ments. } \\
\text { Rehabilitation }\end{array}$ & $\begin{array}{l}\text { Nursing staff, physiotherapist and occupational therapist inde- } \\
\text { pendently assessed patients' }(\mathrm{n}=70) \text { appropriateness of admis- } \\
\text { sion to rehabilitation after discharge. Patients deemed appropri- } \\
\text { ate had much greater FIM efficiency. }\end{array}$ \\
\hline Cunningham [9] & 2000 & UK & $\begin{array}{l}\text { Prospective } \\
\text { cohort }\end{array}$ & $\begin{array}{l}\text { Mixed impairments } \\
\text { (geriatric). } \\
\text { Rehabilitation }\end{array}$ & $\begin{array}{l}\text { Geriatrician, nurse, physiotherapist and occupational therapist } \\
\text { independently assessed patients' }(\mathrm{n}=27) \text { rehabilitation potential } \\
\text { within } 3 \text { days of admission to rehabilitation. Poor agreement } \\
\text { found between staff. }\end{array}$ \\
\hline Unsworth [10] & 2001 & Australia & $\begin{array}{l}\text { Prospective } \\
\text { cohort }\end{array}$ & $\begin{array}{l}\text { Stroke and ortho- } \\
\text { paedic (geriatric, } \\
\geq 60 \text { years) patients. } \\
\text { Acute hospital }\end{array}$ & $\begin{array}{l}\text { FIM and other items assessed } 3 \text { days prior to discharge in acute } \\
\text { hospital patients }(\mathrm{n}=223 \text { stroke, } \mathrm{n}=125 \text { orthopaedic) used to } \\
\text { predict discharge destination from acute hospital. }\end{array}$ \\
\hline Poulos [11] & 2007 & Australia & $\begin{array}{l}\text { Prospective } \\
\text { cohort }\end{array}$ & $\begin{array}{l}\text { Mixed impair- } \\
\text { ments. } \\
\text { Acute hospital }\end{array}$ & $\begin{array}{l}\text { Comparison of rehabilitation physician determination of readi- } \\
\text { ness for transfer of patients }(\mathrm{n}=242) \text { from acute hospital to } \\
\text { rehabilitation with a utilization review tool. Reductions in acute } \\
\text { hospital LOS with the utilization review tool. }\end{array}$ \\
\hline Zhu [12] & 2007 & Canada & $\begin{array}{l}\text { Prospective } \\
\text { cohort }\end{array}$ & $\begin{array}{l}\text { Mixed impair- } \\
\text { ments. } \\
\text { Community dwell- } \\
\text { ing older adults }\end{array}$ & $\begin{array}{l}\text { Description of the development of an algorithm to predict reha- } \\
\text { bilitation potential in community-dwelling older adults }(\mathrm{n}= \\
24,724) \text { better than a clinical assessment protocol. }\end{array}$ \\
\hline Davidoff [13] & 1988 & USA & $\begin{array}{l}\text { Retrospective } \\
\text { cohort }\end{array}$ & $\begin{array}{l}\text { Potential rehabilita- } \\
\text { tion patients. } \\
\text { Acute hospital }\end{array}$ & $\begin{array}{l}\text { Acute hospital referral }(\mathrm{n}=107) \text { for rehabilitation or physiother- } \\
\text { apy only, poorly predicted need for rehabilitation based on } \\
\text { consultation request narrative compared to medical file review } \\
\text { by rehabilitation consultant. }\end{array}$ \\
\hline $\begin{array}{c}\text { Elesha-Adams } \\
{[14]}\end{array}$ & 1983 & USA & NA & Mixed & $\begin{array}{l}\text { Description of preadmission screening and patient orientation } \\
\text { program preceding admission to rehabilitation. }\end{array}$ \\
\hline Caplan [15] & 1987 & USA & NA & Rehabilitation & $\begin{array}{l}\text { Discussion of ethical and policy issues in rehabilitation medi- } \\
\text { cine, including patient selection. }\end{array}$ \\
\hline Haas [16] & 1988 & USA & NA & Rehabilitation & $\begin{array}{l}\text { Description of the process of selection of patients for rehabilita- } \\
\text { tion, with a focus on the ethical implications. }\end{array}$ \\
\hline Dougherty [17] & 1991 & USA & NA & Rehabilitation & $\begin{array}{l}\text { Description of the importance of values in rehabilitation, includ- } \\
\text { ing the issue of ethical fairness needed in selection of patients. }\end{array}$ \\
\hline
\end{tabular}




\begin{tabular}{|c|c|c|c|c|c|}
\hline Author & Year & Country & Study Type & Patients/Setting & Summary \\
\hline Rentz [18] & 1991 & USA & NA & Geriatric patients & $\begin{array}{l}\text { Description of cognitive factors in the assessment of rehabilita- } \\
\text { tion potential in geriatric patients, including useful definitions of } \\
\text { key terms. }\end{array}$ \\
\hline Caplan [19] & 1997 & USA & NA & $\begin{array}{l}\text { Rehabilitation } \\
\text { patients }\end{array}$ & $\begin{array}{c}\text { Description of the ethics of the gatekeeper role in rehabilitation } \\
\text { medicine. }\end{array}$ \\
\hline Golding [21] & 2002 & UK & NA & $\begin{array}{l}\text { Rehabilitation } \\
\text { patients }\end{array}$ & $\begin{array}{c}\text { Description of the process of implementing and evaluating the } \\
\text { role of a nurse in the assessment of potential rehabilitation } \\
\text { patients. }\end{array}$ \\
\hline Wade [22] & 2003 & UK & NA & $\begin{array}{l}\text { Rehabilitation } \\
\text { patients }\end{array}$ & $\begin{array}{l}\text { Description of the difficulties in selecting patients for rehabilita- } \\
\text { tion using defined criteria. Statistical and epidemiological prin- } \\
\text { ciples presented to highlight concepts. }\end{array}$ \\
\hline Buntin [24] & 2007 & USA & NA & $\begin{array}{l}\text { Postacute care, } \\
\text { including } \\
\text { rehabilitation }\end{array}$ & $\begin{array}{l}\text { Overview of the variation in the use of postacute care and } \\
\text { discussion of influence of provider payment on access to care. }\end{array}$ \\
\hline Johnston [25] & 2007 & USA & NA & $\begin{array}{l}\text { Postacute care, } \\
\text { including } \\
\text { rehabilitation }\end{array}$ & $\begin{array}{l}\text { Evaluation of the quality of measurement evidence available for } \\
\text { designing a uniform postacute assessment tool. Includes a } \\
\text { section on domains to be assessed for rehabilitation placement } \\
\text { and an appraisal of a stroke placement algorithm. }\end{array}$ \\
\hline $\begin{array}{l}\text { Ottenbacher } \\
{[26]}\end{array}$ & 2007 & USA & NA & $\begin{array}{l}\text { Postacute care, } \\
\text { including } \\
\text { rehabilitation }\end{array}$ & $\begin{array}{l}\text { Review of access to postacute care rehabilitation services. In- } \\
\text { cludes classification of access issues into } 4 \text { categories: financial, } \\
\text { personal, structural and attitudinal. }\end{array}$ \\
\hline
\end{tabular}

LOS = length of stay, FIM = functional independence measure, NA = not applicable.

Assessment by a rehabilitation physician is not necessary in every situation. Patients most likely to benefit are those who have serious conditions or for who it will be weeks before they are medically stable enough to transfer to rehabilitation (Table 2). Ideally, these patients should be referred for an opinion from a rehabilitation consultant on admission to hospital or upon diagnosis. The advantages of the rehabilitation consultation will be discussed below.

In many settings nurse practitioners have taken on the role of patient selection, often with supplementary screening by rehabilitation consultants $[3,21]$ and sometimes complemented by other members of the multidisciplinary team [14]. Nurses performing these assessments need to have a thorough understanding of the assessment considerations and be experienced in rehabilitation. Nurse assessors lack the specialist rehabilitation medicine expertise of rehabilitation consultants or senior trainees and may have less proficiency in providing a consultative opinion beyond assessment of appropriateness for rehabilitation and setting. From personal experience, patients with elective joint arthroplasty or limb fractures and those needing cardiac or pulmonary rehabilitation are probably most suited for assessment by a rehabilitation nurse assessor. The cost of employing nurse assessors is much less than medical staff. Employing suitably trained and experienced rehabilitation nurse assessors can facilitate a more efficient assessment process.

In some complex situations it is ideal to be able to involve other senior members of the rehabilitation team in the assessment of potential rehabilitation patients in acute hospitals. This can also be useful to assist with planning the transi- tion to rehabilitation and early management strategies to optimize outcomes for the patient and team. This approach is particularly helpful where the acute hospital allied health expertise is limited and the time before transfer to rehabilitation is estimated to be relatively long.

\section{When to Refer for Rehabilitation?}

Ideally, patients should be referred for rehabilitation as early as possible, and not just when they are medically stable. This applies particularly to the impairments listed in Table 2. The country that has the best-established system for early transfer to rehabilitation is the USA. This is largely driven by cost. Health care is much more expensive in acute than postacute (sub-acute) hospitals, such as rehabilitation and geriatric units. Furthermore, because there is increasing evidence that the sooner patients start rehabilitation the better their outcomes [38-40] there is added incentive to transfer patients to rehabilitation as soon as they are ready.

Table 2. Impairments Groups Most Likely to Benefit from Early Involvement of Rehabilitation Physician

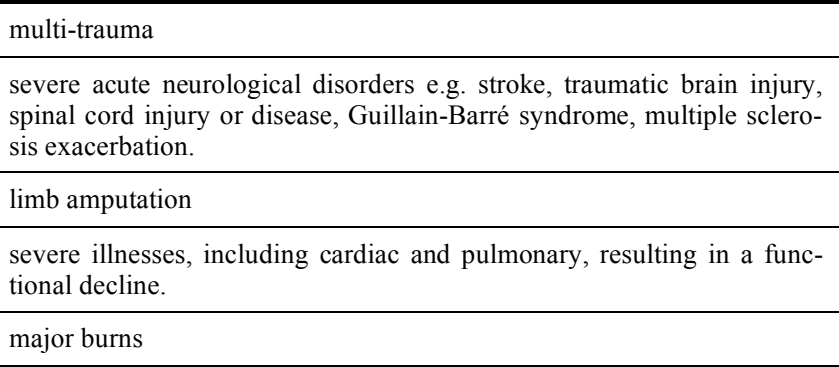


Information technology can help improve aspects of the rehabilitation referral, assessment and triage process. The time patients wait to be deemed medically stable and be transferred to postacute or community-based care can be reduced by implementing a utilization review process to stratify patients care needs [41]. This has been trialed in rehabilitation settings with positive benefits $[4,11]$. Some hospitals use online referral and computerized documentation of assessments in the triage processes to deliver a more efficient process [42]. A recent development in the community rehabilitation of older-aged adults that may have potential for inpatient rehabilitation in the future is the development of an algorithm to predict rehabilitation potential [12].

\section{What Needs to be Assessed in Acute Hospital Patients Regarding the Need for Inpatient Rehabilitation?}

The process of assessing acute hospital patients for rehabilitation usually starts with referral by a member of the acute hospital team, often nursing or medical. The referrer may write a formal referral or complete a local proforma giving key details regarding premorbid and current medical and function status. Sometimes the request is made verbally. The assessor should review the patients' medical file to confirm key details, including relevant investigations, and have discussions with the treating medical, nursing and allied health staff, as appropriate. In addition to seeing the patient, sometimes it is also important to meet with the family.

The assessment of patients in acute hospital for rehabilitation needs to be broad, comprehensive, and conducted from a bio-psycho-social perspective. It does not, however, need to be as detailed as the extensive multidisciplinary assessments conducted after patients are transferred to rehabilitation. The assessment must cover the following: active medical conditions; functional abilities and critical activity limitations; family and social supports; psychological, cognitive, emotional and behavioral issues; and the home environment, especially regarding access, internal barriers and the toilet and bathroom set-up [27, 29-31, 43-45].

\section{Medical and Nursing Factors}

The assessment of acute hospital patients for rehabilitation needs to cover numerous medical factors. These include: the presenting disease diagnosis and complications, prognosis, and management issues; the resulting impairments and related symptoms; and subsequent activity limitations. Major active comorbid diseases, treatments, and related functional limitations are also an important consideration as they can limit the potential to participate in rehabilitation (Table 3). Participation restrictions, although important to the adjustment process and longer-term rehabilitation goals, are not a focus in determining the necessity for inpatient rehabilitation. A focused but thorough examination of relevant systems is also important. This may identify examination errors or omissions made by the acute hospital staff. If the patient is subsequently admitted to rehabilitation comparison can be made with the initial examination in order to determine intervening improvement, or to aid in detecting deterioration sooner. This applies especially to patients with neurological impairments.

Patients need to be medically stable in order to participate in rehabilitation. Criteria for medical stability, however, can differ from one setting to another. For example, patients with a tracheostomy cannot be managed in all rehabilitation centers. It is suggested that patients who have a tracheostomy removed in the acute hospital wait a minimum of 24 hours before they are transferred to rehabilitation in case there is deterioration if the rehabilitation ward is not colocated with an acute hospital. The burden of nursing care and ability of the rehabilitation unit to cope with patients who have high-level or specialist care needs will vary in different settings. This necessitates a good understanding of the local resources and communication between relevant staff in all situations of uncertainty. Arrangements should be made to address circumstances where specialist or complex care and equipment requirements exist (e.g. oxygen, bariatric equipment, single rooms for patients with infections requiring isolation etc) before the patient is transferred. Sometimes this may necessitate a delay in the transfer of a patient (See

Table 3. Examples of Comorbid Medical Conditions and how they can Impact on Participation in Rehabilitation

\begin{tabular}{|l|l|}
\hline \multicolumn{1}{|c|}{ Comorbid Diagnosis } & \multicolumn{1}{|c|}{ Impact on Rehabilitation Participation } \\
\hline \hline Obesity & $\begin{array}{l}\text { Endurance/exertion, mobility \& transfers, need for more expensive bariatric equipment, increased burden of } \\
\text { nursing care, increased risk of complications, difficulty obtaining aids, equipment and home modifications } \\
\text { necessary for discharge. }\end{array}$ \\
\hline Cardiac diseases & Endurance/mobility limitations \\
\hline Respiratory & Endurance/mobility limitations \\
\hline Sleep disordered breathing/sleep apnea & Endurance/mobility limitations, cognitive impairment, attention/concentration \\
\hline Arthritis & Pain, mobility and transfers \\
\hline Peripheral vascular disease & Skin integrity, endurance/mobility \\
\hline Chronic pain & Participation in all facet of inpatient rehabilitation \\
\hline Renal failure/dialysis & Risk infections, endurance/mobility, interruptions to rehabilitation participation if having dialysis \\
\hline Alcohol/drug abuse & Cognitive, behavior and personality challenges to participation in rehabilitation \\
\hline $\begin{array}{l}\text { Mood and personality disorders, } \\
\text { schizophrenia }\end{array}$ & Behavior and personality challenges to participation in rehabilitation \\
\hline Dementia & Cognitive, behavior and personality challenges to participation in rehabilitation \\
\hline
\end{tabular}


'pre-admission meeting' below). The risks and benefits of the delay need to be evaluated in each situation according to local circumstances.

The level of specialist medical and surgical services and radiological imaging available at rehabilitation hospitals also varies. Therefore, it is important that significant comorbid medical issues requiring consultation with medical or surgical units have been satisfactorily addressed before the patient is transferred to rehabilitation. Likewise, all necessary investigations that are required before the patient will be able to be managed safely in rehabilitation without the ready access to tertiary medical services should be completed before transfer.

\section{Psychological Factors}

Psychological and psychiatric factors in the context of rehabilitation assessment focus on excluding patients with conditions that are barriers to participation in the rehabilitation program. These include extremely disruptive personality disorders, severe intellectual disability with troublesome behaviors, disruptive drug or alcohol addiction, and active schizophrenia. Patients with these conditions can often be stabilized, and with appropriate supports for the rehabilitation team, they can subsequently be adequately managed in rehabilitation. The necessity of having the adequate supports for the rehabilitation team cannot be underestimated in these situations.

Patients with grief reactions, adjustments disorders or depressive illness are another challenge. Patients with severe depression will not be able to participate fully in a rehabilitation program. Unless they are suicidal, however, the ideal setting for the management of these patients in most cases is probably still a rehabilitation center. With appropriate psychiatric and psychological support and antidepressant medication, these patients are usually able to be managed and participate in a rehabilitation program. Furthermore, therapy focused on improving their function can possibly assist in improving their mood.

Patients with cognitive problems are a special issue. If restoration is not possible, many rehabilitation activities are reliant on the ability of a patient to learn new approaches to compensate for persisting activity limitations and participation restrictions. The context of the cognitive dysfunction, however, is a major factor in determining the weight given to its' importance when considering appropriateness for rehabilitation. For example, patients with cognitive deficits due to acquired brain injury are appropriate for specialized units targeting these patients. It is important to point out that patients with dementia still have the potential to participate in and benefit from rehabilitation [46]. Patients with moderate to severe dementia, however, may have more limited goals and be more appropriate for a lower intensity rehabilitation program, such as a Skilled Nursing Home or a geriatric unit.

\section{Social Factors}

Social factors and supports are important considerations in rehabilitation assessments. Patients with stronger family, social and financial supports have better rehabilitation outcomes $[47,48]$ and are less likely to be discharged to institutionalized care $[5,10,49]$.
The assessment of patients' financial resources is a consideration in a user-pays health care system that relies on fee for service health care funding, such as the USA. Some countries have health care systems with both public and private hospitals. If the private insurance coverage for inpatient rehabilitation is time-limited, then, if it is apparent that the estimated LOS for a patient is going to be greater than that covered by the insurance this should be discussed with the patient. It may be more appropriate in these circumstances for the patient to be advised that a public rehabilitation hospital may be more ideal. This is because of the disruption to the rehabilitation process and the time required to reestablish rapport between therapists and the patient (and family) when changing hospitals if the patient or family does not have sufficient financial resources to pay for the ongoing out of pocket expenses. It can be difficult to determine, however, early post-onset of the triggering event and while the patient is still in acute hospital the likely LOS in rehabilitation.

\section{Objectivity, Subjectivity, and Practical Aspects of the Selection Process}

It has been argued that there is a need for more objective patient selection criteria for rehabilitation [16]. The goal of the selection process can vary, however, between settings. For example, the purpose may be to select patients with the best potential to make functional gains, have the shortest length of stay, or have the best outcomes, including avoiding admitting patients who may require institutional care after rehabilitation $[5,10]$.

It has been noted that the selection of patients can become more or less stringent according to the availability of beds [16]. It has also been reported that referral to rehabilitation or other postacute care facilities is strongly related to proximity of the nearest postacute care facility, regardless of the clinical characteristics of patients [23]. The role of nonclinical factors in selecting patients has been noted previously $[16,34]$ and discussed in detail by others $[24,50]$. A recent review of access to postacute care rehabilitation services classified indicators of access into 4 categories: financial, personal, structural and attitudinal [26]. The influence of financial factors on patient access to rehabilitation in the USA has been recently reviewed [24]. It has been highlighted that the prospective payment of rehabilitation providers and the use of non evidence-based funding restrictions have a large influence on patient selection in that country. In particular, the requirement $75 \%$ of patients in an inpatient rehabilitation facility fall into one of ten groups for the facility to be certified [24] and that patients must be able to tolerate a minimum of 3 hours a day of active therapy to be eligible for intensive, acute rehabilitation [51].

In an effort to increase objectivity in selecting patients for rehabilitation some authors have advocated the use of the Functional Independence Measure (FIM) [52] on admission [7] or prior to discharge [10] from acute hospital to assist in selecting patients most likely to benefit and who will not require nursing home placement after rehabilitation. A non evidence-based generic algorithm for the selection of rehabilitation patients into differing postacute care settings, including inpatient rehabilitation, has been developed in the USA [25]. Although it is not applicable for use in other 
countries because of the differing arrangements for funding and organization of postacute care, this algorithm was developed by a large group of experts and does offer a useful framework for further research in this area.

The difficulties in developing objective criteria for selecting rehabilitation patients has been highlighted [22]. A strong argument has been made for the viewpoint that formal criteria are likely to either select too many inappropriate patients or exclude too many appropriate patients. An important issue in this decision making is that the categorical question of whether a patient is appropriate for rehabilitation overlooks that there are actually two considerations. First, the probability of a patient benefiting from rehabilitation, and second, the likely extent of that benefit.

\section{Trial of Rehabilitation}

In circumstances where resources are restricted it is necessary to be more selective in the patients admitted. Many patients with severe disabilities, however, still have the potential to make significant functional gains or to be discharged home with the help of supportive families [53, 54]. It can be argued that improving the outcomes of the severely disabled is more attractive from a health-economics and social perspective. Instead of these patients going to institutional care, if more could be returned to their families or a lower level of care, then the financial and social benefits would be considerable.

One approach to dealing with the uncertainties of the ability of a patient to benefit from rehabilitation, and their family to provide care at home, is to admit patients' for a 'trial of rehabilitation'. Typically, this involves a period of 46 weeks of inpatient rehabilitation during which assessments and therapy are provided and the benefit noted. Progress is monitored and discussed in team meetings. A decision is made at the end of the agreed trial period, which is communicated in a family meeting, regarding whether to continue with the rehabilitation program or to arrange transfer to a high-level care facility, or another more suitable alternative facility. In this way patients can be given an opportunity to achieve optimal outcomes and the ethical tension between utility and beneficence can be diffused. This approach works best when there are adequate services available in a timely manner to continue to care for patients if they are not able to benefit from rehabilitation. These include options such as
Skilled Nursing Facilities or nursing home options that are suitable for both younger and older adults with complex care needs.

Reliability science suggests that non-catastrophic health care processes are impossible to engineer to extremely low "failure" rates [55]. This applies particularly to the difficulties in selecting patients for rehabilitation. What is suggested is to accept less than perfect selection and add layered "failure prevention". Then design effective feedback into the selection process. This has not been reported in the rehabilitation assessment process.

\section{Pre-Admission Meeting}

Another benefit of the rehabilitation assessment process is to identify patients likely to have poor participation or present particular challenges to the treating team. These patients are more likely to have worse rehabilitation outcomes [56]. If there are circumstances or indicators that this is likely, then a useful strategy is to establish a process of arranging either a 'pre-admission meeting' or an early 'treatment planning meeting' (immediately after admission) with the treating team or senior therapists, nursing and medical staff. This process allows early planning to begin in order to establish strategies to try and optimize patients' participation and address issues as soon as possible.

\section{'Traffic Light' Approach to Admission}

One approach to aid in the selection of patients for rehabilitation is to consider a 'traffic light' classification as a way of flagging patients less likely to benefit from rehabilitation or who pose particular challenges to the rehabilitation team, and those more likely to be suitable. The type of patients under each of the colors would be determined by the individual service. Some suggestions are provided in Table 4. As part of this triage process it is suggested that consideration be given to all patients who are orange or red light having a pre-admission meeting to consider the referal and discuss appropriate management strategies. Alternatively, an early treatment-planning meeting can also be held if it is agreed the patient concerned is to be admitted.

\section{The Need for Rehabilitation and where should it Occur}

If it is believed that the patient is not yet ready for transfer to rehabilitation because of ongoing medical issues that

Table 4. Suggested 'Traffic Light' Classification of Patient Appropriateness for a Rehabilitation Program

\begin{tabular}{|c|c|c|}
\hline $\begin{array}{c}\text { Green Light } \\
\text { (Admit Always) }\end{array}$ & $\begin{array}{c}\text { Orange Light } \\
\text { (Consider with Caution) }\end{array}$ & $\begin{array}{c}\text { Red Light } \\
\text { (Not Appropriate) }\end{array}$ \\
\hline \hline $\begin{array}{c}\text { Acute onset illness or surgical event resulting } \\
\text { in severe activity limitations that restricts } \\
\text { ability of patients to return home. Willing to } \\
\text { participate in rehabilitation. Previously living } \\
\text { in community. }\end{array}$ & Conversion disorders & $\begin{array}{c}\text { Limited life expectancy. e.g. <3 months (Con- } \\
\text { sider palliative care) }\end{array}$ \\
\hline & Personality disorders & $\begin{array}{c}\text { Patient makes informed decision to refuse, and } \\
\text { is competent to do so }\end{array}$ \\
\hline & $\begin{array}{c}\text { Obese patients requiring bariatric equipment not rou- } \\
\text { tinely available }\end{array}$ & $\begin{array}{c}\text { Severe dementia (Consider Skilled Nursing } \\
\text { Facility or Geriatric rehabilitation unit) }\end{array}$ \\
\hline & $\begin{array}{c}\text { Patients with special nursing care needs not routinely } \\
\text { managed in the rehabilitation unit e.g. patients with } \\
\text { tracheotomy }\end{array}$ & \\
\hline
\end{tabular}


require treatment or investigation in acute hospital, then these concerns should be discussed with the treating team. The patient should be reviewed in a timely fashion after the issues are resolved.

If it is felt that the patient is not appropriate for inpatient rehabilitation at all, then reasons should be given. Suggestions should be made regarding possible options that are felt to be more appropriate. These include alternatives such as palliative care, nursing home, a Geriatric unit, or a Skilled Nursing Facility, depending on the available options in the specific country or region. In these situations it may also be appropriate to indicate that a re-assessment can be arranged if certain criteria are met that suggests the patients' ability to benefit has changed. If the patient or family disputes the assessment decision then there is an ethical responsibility to facilitate a second opinion $[16,17,20]$.

If the patient needs rehabilitation then a decision needs to be made regarding in which setting this should occur. As well as inpatient rehabilitation, other options may include outpatient center-based rehabilitation, domiciliary rehabilitation, or if available, a combination of both of these simultaneously. In general, if available, rehabilitation should be provided in the home or local rehabilitation center if the following criteria are met: the home is readily accessible and there are no practical environmental barriers to the bathroom and toilet; there are no patient safety concerns, including cognitive, swallowing, nutritional and communicative, and the activity limitations and burden of care on family is not excessive. If the patient is felt to need inpatient rehabilitation, then a decision also needs to be made regarding where this should occur. Patients with certain impairments may need sub-specialty programs, such as burns, spinal cord injury, stroke and other causes of acquired brain injury, or limb amputation.

\section{Consultative Considerations}

Although consultations are a crucial component of physician practice [57], including rehabilitation, there has been very little discussion in the rehabilitation literature about consultative considerations in rehabilitation practice $[35,36]$. This applies especially to the rehabilitation assessment performed on acute hospital patients. As mentioned above, a comprehensive assessment should include, in addition to an opinion regarding the need for and setting of rehabilitation, a consultative component that gives specific suggestions regarding patient management strategies that can optimize outcomes.

Early active involvement of rehabilitation staff during the acute hospital phase can have numerous benefits. It has been suggested that this involvement may shorten the LOS in hospital and prevent complications [36], although no controlled studies have been located that test this hypothesis. The rehabilitation assessor can help give the patient a better understanding of the rehabilitation process, including expectations of rehabilitation staff. This may improve patient adjustment and smooth the transition to rehabilitation.

The utility for a consultative role for rehabilitation medicine probably varies from one health care setting to another, and may also vary between different impairment groups. In some health care systems there is a very efficient process (i.e. one or two days) for acute hospital patients to be deemed medically stable and assessed regarding rehabilitation need and for subsequent admission to inpatient rehabilitation. In these settings, the potential benefit, especially for patients who have had elective orthopedic procedures, is probably more limited.

\section{Specific Education of Acute Hospital Staff Regarding Indi- vidual Patient Requirements}

A case has been made above regarding the early referral of certain patients for an opinion from a rehabilitation specialist. For these patients the rehabilitation assessor should make specific recommendations to the acute hospital staff regarding treatments, therapies, and management strategies that can prevent complications and optimize rehabilitation outcomes. The potential benefits from the early involvement of a rehabilitation medicine consultation are listed in Table 5.

The rehabilitation assessor can also recommend the involvement of allied health professionals in the acute phase, where they are not routinely involved. The allied health staff can complement the expertise of the rehabilitation consultant and start important rehabilitation process while the patient is receiving necessary medical treatments or waiting for a rehabilitation bed. For example, conducting a home visit to access for necessary modifications in order to facilitate discharge home in cases where this is the obvious discharge destination. This way the process of obtaining quotes and making the necessary modifications can be commenced earlier and possibly remove this as a cause for potential delay in discharge from rehabilitation.

\section{General Education of Acute Hospital Staff}

Rehabilitation staff in acute hospitals can have an indirect educative benefit for acute hospital medical, nursing and allied health professionals. There would be opportunities for learning principles of rehabilitation that the acute hospital staff could then apply to other patients that they encounter in their clinical practice, with benefits for these patients'. Acute hospital staff do not always have a good understanding of the need for rehabilitation [13]. Therefore, a visible and proactive rehabilitation presence in acute hospitals may help to address this deficiency and increase the referral of appropriate patients for rehabilitation.

\section{Patient and Family Education}

\section{Program and Impairment Information}

Details concerning the specific rehabilitation service or program that the patient will be admitted into can be helpful for both patients' and their family. A pamphlet can be a convenient way of presenting this information. This can be used to shorten the consultative process, by including procedural and practical information, such as rehabilitation unit location, transport options, visiting hours, the need to wear comfortable and loose-fitting clothes suitable for exercising and not pajamas, etc.

Patients and their family can potentially have impaired memory because of the stress and anxiety experienced during the acute phase of their illness. Therefore, in addition to a verbal explanation, pamphlets or information booklets can 
Table 5. Potential Benefits from the Early Involvement of Rehabilitation Medicine Consultation

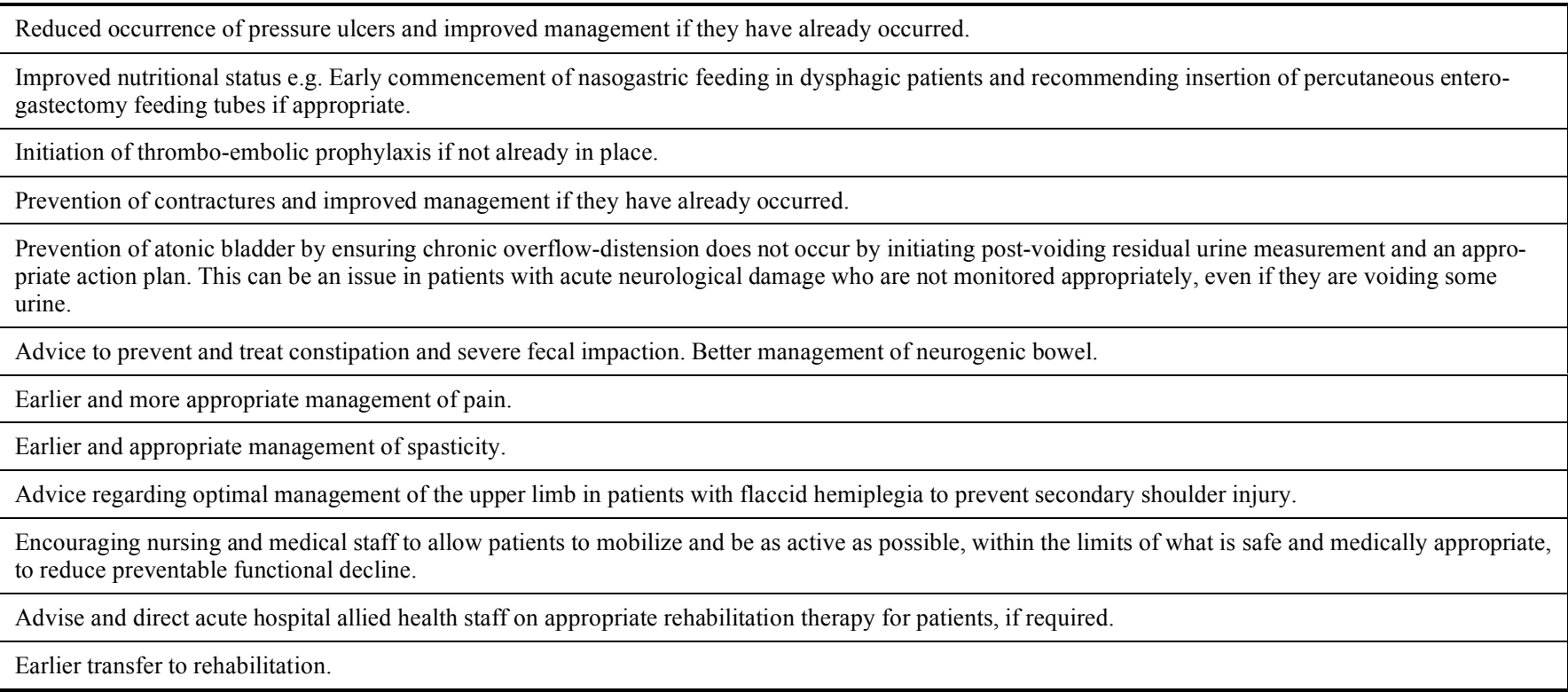

also be used to give basic education regarding the impairment and its' rehabilitation implications.

\section{Expectations of Inpatient Rehabilitation}

An explanation of the expectations of inpatient rehabilitation programs can be very helpful to patients after they have been assessed and accepted for rehabilitation. Many patients have little or no understanding of what rehabilitation involves and how the approach and focus of care is different from that provided in acute hospitals. In particular, education can be particularly useful regarding the following: the role of nursing staff (washing, dressing and feeding patients in acute hospital compared with encouraging patients to do as much as possible that they are safe to); the location of where meals are eaten (typically in bed in acute hospital compared with a dinning room or sitting out of bed in rehabilitation) and the type of clothes worn by patients (pajamas in acute hospital compared with casual comfortable clothes in rehabilitation) etc. This sort of information can also be included in a pamphlet for patients.

Another area that is important to cover, for both the patient and acute hospital, is an estimated waiting time for a rehabilitation hospital bed. This can sometimes be a difficult question to answer exactly. Nevertheless, it is still appropriate to give a qualified answer and an estimated time frame in order to set realistic expectations and address potential anxiety surrounding any delay.

\section{Prognosis and Estimated Length of Stay}

Two of the most important concerns for patients in hospital are how long they will an inpatient and what is their prognosis for recovery. These can sometimes be very hard to answer. Acute hospital staff may be pressured into giving their opinion, or they may want to well meaningfully reassure the patient. Unfortunately, this can lead to the patient being given either unrealistic expectations or an overly pessimistic prognosis. Both of these can have adverse psychological consequence for the patient and their family, and their ability to work optimally with the rehabilitation team to set and achieve realistic goals $[58,59]$. Therefore, if the person performing the rehabilitation assessment is a rehabilitation specialist, or an experienced rehabilitation nurse or trainee, and they feel confident in giving an opinion after completing the rehabilitation assessment, it is suggested that they should give a qualified answer.

In other circumstances, the most appropriate response may be to not answer in any specific detail, but to advise that an estimate will be given after the initial assessment and team meeting following admission to the rehabilitation hospital. For example, by explaining that 'Every patient is different, and it is still very early in your recovery. The aim is always to try and get you home as soon as it is safe and you are able to cope with what you need to do to manage, or have services arranged to assist you where necessary. It may be a number of weeks/months before this is possible. It will become more apparent after you are admitted to rehabilitation and commence more intensive therapy. The team working with you will give you an indication within the first week or so of your admission how long this will take.'

\section{Patient Education Regarding Optimizing Function}

In some situations it can be very useful to give patients' specific information about strategies they can implement to improve their function and prevent complications. Examples of this include information on pressure ulcer prevention, shoulder care to prevent damage due to inappropriate transfer techniques, knee range of motion activities in arthroplasty patients, and upper limb strengthening for patients with paraplegia. This information is complementary and additional to the education given to acute hospital staff.

\section{CONCLUSION}

The assessment of patients in acute hospital for potential inpatient rehabilitation is a skill that takes years to fully develop. It has the potential to improve patient outcomes by facilitating the transfer from acute hospital to the most appropriate setting for ongoing care in the timeliest manner, initiating and guiding appropriate interventions in the acute 
hospital, and ensuring that strategies to prevent complications are implemented.

There is a need for further research to increase the evidence-base regarding rehabilitation assessments in acute hospital. More than 20 years ago the dearth of literature on this topic was noted [16], and there has been little progress in addressing this in the intervening years. Factors that make research in this area more challenging include the nuances of national, regional and local practices and factors that influence resource availability to deliver rehabilitation assessment services in acute hospitals.

It is suggested that a formal process for establishing a consensus opinion from a panel of experts could be organized to help provide guidance in some aspects of selection of patients for rehabilitation. This would help address the subjectively of some of the suggestions made here in the setting of limited evidence in the exiting literature on this topic. This could provide direction to rehabilitation consultants and program manages while awaiting better quality studies to emerge. Ideally, this panel should have an international representation. In addition, this panel could also develop a classification system for rehabilitation programs. This would help facilitate comparison studies of rehabilitation medicine in different countries and international multicenter intervention studies.

It is recommended that future studies on the selection of patients for rehabilitation should be conducted on how best to triage patients from acute hospital into rehabilitation. The use of information technology and computer modeling systems in patient selection also has potential, as mentioned above, that should be explored. Studies on the anticipated benefit of early rehabilitation team involvement in the management of acute hospital patients' compared to outcomes from services limited to an assessment of the need for rehabilitation are also warranted.

\section{ACKNOWLEDGEMENTS}

This paper is the culmination of many years of experience and reflection on the role of rehabilitation medicine in the acute health care system. I am indebted to all my teachers and mentors over the years, and thank them all again.

The following people contributed to this paper, and their efforts are gratefully appreciated. Veronica Delafosse, senior librarian Caulfield Hospital, Alfred Health, Melbourne, Victoria, Australia, assisted with the literature search. Dr. Brian Anthonisz, Caulfield Hospital, suggested a concept that led to the 'Traffic Lights' for admission model. Dr. Fary Kahn, Royal Melbourne Hospital, Melbourne, provided helpful suggestions on an earlier draft of this manuscript. Keith Stockman and Fiona Dickson, from the Monash Institute of Health Science Research, Melbourne, also provided helpful advice.

The reviewers of the initial version of this manuscript are also acknowledged for their helpful suggestions.

\section{CONFLICT OF INTERESTS}

No conflicts of interest to declare. No support in the form of grants, equipment or drugs was provided as part of this paper.

\section{REFERENCES}

[1] United Nations. Report of the Second World Assembly on Ageing; 2002; Madrid, 8-12 April 2002: United Nations, New York 2002.

[2] Feingeson JS, McCarthy ML, Greenberg SD, Feingeson WD. Factors influencing outcome and length of stay in a stroke rehabilitation unit: part 2. Comparison of 318 screened and 248 unscreened patients. Stroke 1977; 8: 657-62.

[3] Poduri KR, Palenski C, Gibson CJ. Inpatient rehabilitation: physiatric and nurse practitioner admission assessment of stroke patients and their rehabilitation outcomes. Int J Rehabil Res 1996; 19: 11121.

[4] Kossovsky MP, Chopard P, Bolla F, et al. Evaluation of quality improvement interventions to reduce inappropriate hospital use. Int J Qual Health Care 2002; 14: 227-32.

[5] Tamler MS, Perrin JCS. Beaumont lifestyle inventory of social support. Can it predict disposition prior to an inpatient rehabilitaiton admission? Am J Phys Med Rehabil 1992; 71: 149-55.

[6] Kala L, Crome P. The role of prognostic scores in targeting stroke rehabilitaiton in elderly patients. J Am Geriatr Soc 1993; 41: 396400.

[7] Mauthe RW, Haaf DC, Hayn P, Krall JM. Predicting discharge destination of stroke patients using a mathematical model based on six items from the Functional Independence Measure. Arch Phys Med Rehabil 1996; 77: 10-3.

[8] Poduri KR, Cushman LA, Gibson CJ. Inpatient rehabilitation: the correlation between functional gains and appropriateness of admissions. Int J Rehabil Res 1996; 19: 327-32. [Erratum appears in Int J Rehabil Res 1997; 20: 110].

[9] Cunningham C, Horgan F, O'Neill D. Clinical assessment of rehabilitation potential of the older patient: a pilot study. Clin Rehabil 2000; 14: 205-7.

[10] Unsworth CA. Selection for rehabilitation: acute care discharge patterns for stroke and orthopaedic patients. Int J Rehabil Res 2001; 24: 103-14.

[11] Poulos CJ, Eagar K, Poulos RG. Managing the interface between acute care and rehabilitation - can utilisation review assist? Aust Health Rev 2007; 31(Supp1 1): 129-40.

[12] Zhu M, Chen W, Hirdes JP, Stolee P. The K-nearest neighbor algorithm predicted rehabilitation potential better than current Clinical Assessment Protocol. J Clin Epidemiol 2007; 60: 1015-21.

[13] Davidoff G, Stolp-Smith KA, Waring WP, Cole TM. Patterns of referral to a university hospital consultation service: failure to accurately predict need for physiatric services. Arch Phys Med Rehabil 1988; 69: 449-50.

[14] Elesha-Adams M, McIntyre K. Facilitating the patient's entry into the rehabilitation setting. Rehabil Nurs 1983; 46: 22-3.

[15] Caplan AL, Callahan D, Haas J. Ethical \& policy issues in rehabilitation medicine. Hastings Center Report Special Suppl 1987; 17: 120.

[16] Haas JF. Admission to rehabilitation centers: selection of patients. Arch Phys Med Rehabil 1988; 69: 329-32.

[17] Dougherty CJ. Values in rehabilitation: Happiness, freedom and fairness. J Rehabil 1991; 1: 7-12.

[18] Rentz DM. The assessment of rehabilitaiton potential: cognitive factors. In: Hartke RJ, Ed. Psychological aspects of geriatric medicine. Gaithersburg, MD: Aspen; 1991.

[19] Caplan A. The ethics of gatekeeping in rehabilitation medicine. J Head Trauma Rehabil 1997; 12: 29-36.

[20] Blackmer J. Ethical issues in rehabilitation. Scand J Rehabil Med 2000; 32: 51-5.

[21] Golding J, Mitchell T. Promoting effective rehabilitation via nurseinitiated patient transfer. Prof Nurs 2002; 17: 496-9.

[22] Wade DT. Selection criteria for rehabilitation services. Clin Rehabil 2003; 17: 115-8.

[23] Buntin MB, Garten AD, Paddock S, Saliba D, Totten M, Escarce JJ. How much is postacute care use affected by its availability? Health Serv Res 2005; 40: 413-34.

[24] Buntin MB. Access to postacute rehabilitation. Arch Phys Med Rehabil 2007; 88: 1488-93.

[25] Johnston MV, Graves D, Greene M. The uniform postacute assessment tool: systematically evaluating the quality of measurement evidence. Arch Phys Med Rehabil 2007; 88: 1505-12.

[26] Ottenbacher KJ, Graham JE. The state-of-the-science: access to postacute care rehabilitation services. A review. Arch Phys Med Rehabil 2007; 88: 1513-21. 
[27] Goodwill CJ, Chamberlain MA, Evans C. Rehabilitation of the Physically Disabled Adult: Stanley Thornes 1997.

[28] Barnes MP, Ward AB. Textbook of rehabilitation medicine. Oxford: Oxford University Press 2000.

[29] Braddom RL. Physical Medicine \& Rehabilitation. $3^{\text {rd }}$ ed. Philadelphia: Saunders Elsevier 2007.

[30] Garrison SJ. Handbook of physical medicine and rehabilitation basics. $2^{\text {nd }}$ ed. Lippincott: Williams 2003.

[31] Rothstein JM, Roy SH, Wolf SL, Scalzitti DA. The Rehabilitation Specialist's handbook. $3^{\text {rd }}$ ed.: F.A Davis Company; Philadelphia 2005.

[32] Tan JC. Practical manual of physical medicine and rehabilitation. $2^{\text {nd }}$ ed. New York: Elsevier Mosby 2006.

[33] Kaplan RJ. Physical medicine and rehabilitation review. McGrawHill; New York 2006.

[34] Haas JF. Ethical issues in rehabilitation medicine. In: DeLisa JA, Ed. Physical Medicine and Rehabilitation. $4^{\text {th }}$ ed. Philadelphia: Lippincott Williams \& Wilkins; 2005; pp. 1086-97.

[35] Grabois M, Bloodworth D, Bodenheimer C. Physical medicine and rehabilitation consultation and prescription writing. In: Grabois M, Garrison SJ, Hart KA, Lehmkuhl LD, Eds. Physical medicine and rehabilitation. The complete approach. Houston, TX: Blackwell 2000: pp. 375-92.

[36] Steins S, Reyes R, Svircev J. The physiatric consultation: acute treatment, immediate rehabilitation, and future enablement. In: O'Young BJ, Young MA, Steins SA, Eds. Physical medicine and rehabilitation secrets. $3^{\text {rd }}$ ed. Philadelphia: Mosby Elsevier 2008; pp. 93-9.

[37] Scofield GR. Ethics and rehabilitation. In: Grabois M, Garrison SJ, Hart KA, Lehmkuhl LD, Eds. Physical medicine and rehabilitation. The complete approach. Houston, TX: Blackwell 2000; pp. 33-47.

[38] Munin MC, Rudy TE, Glynn NW, Crossett LS, Rubash HE. Early inpatient rehabilitation after elective hip and knee arthroplasty. JAMA 1998; 279: 847-52.

[39] Maulden SA, Gassaway J, Horn SD, Smout RJ, DeJong G. Timing of initiation of rehabilitation after stroke. Arch Phys Med Rehabil 2005; 86(12 Suppl 2): S34-40.

[40] Scivoletto G, Morganti B, Molinari M. Early $v s$ delayed inpatient spinal cord injury rehabilitation: an Italian study. Arch Phys Med Rehabil 2005; 86: 512-6.

[41] McDonagh MS, Smith DH, Goddard M. Measuring appropriate use of acute beds. A systematic review of methods and results. Health Policy 2000; 53: 157-84. [Erratum in: Health Policy 2000; 54: $163]$.

[42] Poulos CJ, Gazibarich BM, Eagar K. Supporting work practices, improving patient flow and monitoring performance using a clinical information management system. Aust Health Rev 2007; 31: S79-85.
[43] Grabois M, Garrison SJ, Hart KA, Lehmkuhl LD. Physical Medicine and Rehabilitation. The complete approach. Blackwell Science; Houston, TX 2000.

[44] O'Young BJ, Young MA, Steins SA, Eds. Physical medicine and rehabilitation secrets. $3^{\text {rd }}$ ed. Philadelphia: Mosby Elsevier 2008.

[45] DeLisa JA. Physical Medicine and Rehabilitation. $4^{\text {th }}$ ed. Lippincott Williams \& Wilkins; Philadelphia 2005

[46] Schuman JE, Beattie J, Steed DA, Merry GM, Kraus AS. Geriatric patients with and without intellectual dysfunction: effectiveness of a standard rehabilitation program. Arch Phys Med Rehabil 1981; 62: 612-8.

[47] Wee JY, Hopman WM. Stroke impairment predictors of discharge function, length of stay, and discharge destination in stroke rehabilitation. Am J Phys Med 2005; 84: 604-12.

[48] San Segundo RM, Aguilar JJ, Santos F, Usabiaga T. A model for predicting delay in discharge of stroke patients. Ann Readap Med Phys 2007; 50: 14-9.

[49] Miller LS, Forer SK, Davis C. Rehabilitation social workers: measuring their ability to predict discharge destination of rehabilitation patients. Arch Phys Med Rehabil 1984; 65: 87-8.

[50] Jette AM, Keysor JJ. Uses of evidence in disability outcomes and effictiveness research. Milbank Q 2002; 80: 325-45.

[51] Johnston MV, Miller LS. Cost-effectiveness of the Medicare threehour regulation. Arch Phys Med Rehabil 1986; 67: 581-5.

[52] Guide for the Uniform Data Set for Medical Rehabilitation (including the FIM instrument), version 5.1. Buffalo, NY: State University of New York at Buffalo; 1997.

[53] Kosasih JB, Borca HH, Wenninger WJ, Duthie E. Nursing home rehabilitation after acute rehabilitation: predictors and outcomes. Arch Phys Med Rehabil 1998; 79: 670-3.

[54] Teasell RW, Foley NC, Bhogal SK, Chakravertty R, Bluvol A. A rehabilitation program for patients recovering from severe stroke. Can J Neurol Sci 2005; 32: 512-7.

[55] Resar RK. Making noncatastrophic health care processes reliable: learning to walk before running in creating high-reliability organizations. Health Serv Res 2006; 41 (4 Pt 2): 1677-89.

[56] Lenze EJ, Munin MC, Quear T, et al. Significance of poor patient participation in physical and occupational therapy for functional outcome and length of stay. Arch Phys Med Rehabil 2004; 85: 1599-601.

[57] Charlton C. Learning to consult. Oxford: Radcliffe Publishing; 2007.

[58] Rosillo RH, Fogel ML. Correlation of psychologic variables and progress in physical rehabilitation. I. Degree of disability and denial of illness. Arch Phys Med Rehabil 1970; 51: 227-33.

[59] Mondloch MV, Cole DC, Frank JW. Does how you do depend on how you think you'll do? A systematic review of the evidence for a relation between patients' recovery expecations and health outcomes. CMAJ 2001; 165: 174-9. 